Technical Note

\title{
The LAST Coring Platform You Will Ever Need: Light, Affordable, Stable, and Transportable
}

\author{
Olivier Blarquez * and Julie Aleman \\ Département de Géographie, Université de Montréal, Montréal, QC H3T 1J4, Canada; julie.aleman@gmail.com \\ * Correspondence: blarquez@gmail.com
}

Received: 24 July 2020; Accepted: 29 August 2020; Published: 9 September 2020

\begin{abstract}
Coring lakes and water bodies for paleoecological studies often involves using a coring platform to properly operate a sediment sampling device. In the past, coring platforms have been developed by specific paleoecology laboratories or by private companies. Those coring platforms are generally composed of two boats (inflatable boats, kayaks, etc.) connected together by a metallic and wood structure. While these coring platforms have proven their efficacy, they are not ideal in several coring settings requiring remote transportation, and their cost may be prohibitive for less funded paleoecological laboratories. On this technical note, we describe the Light, Affordable, Stable, and Transportable (LAST) coring platform. Coring platforms based on these principles and on the design presented herein have been extensively tested in various conditions and countries by our research group and collaborators. In the first part of this manuscript, we present the principles and the design of the LAST coring platform; then, we discuss the coring setting for which the LAST coring platform is suitable, and its possible limitations. Associated with this manuscript, we provide a construction and assemblage manual developed without words and with simple illustrations in order to make it easily accessible to speakers of any language.
\end{abstract}

Keywords: coring platform; lake; river; paleoecology

\section{Introduction}

Coring lakes, rivers, and streams for terrestrial paleoecological studies, when not done during winter on a frozen surface, generally involves using a coring platform or some boats. The coring platform should provide a stable working area from which a sediment sampling device is operated. Most of the existing coring platforms are based on two boats connected together by a wood and/or metallic structure [1]. For example, the LacCore R/V KRKII [2] is a relatively large and heavy coring platform requiring a shipping container for transportation or towing by a heavy truck. Commercially available coring platforms from Uwitec [3] are also generally heavy and require an important logistic to transport and deploy. They are nonetheless essential for coring very deep lakes with highly consolidated sediments such as the Lake Barombi Mbo in Cameroon [4]. These coring platforms are generally very stable and have been proven useful in various settings [5], but their cost may be prohibitive, and the organization on transportation may be complicated.

Except for very deep lakes such as crater lakes, most paleoecological studies tend to analyse small lakes and water bodies with water depths generally not exceeding ten meters. The sediment of those small water bodies may be composed of consolidated clay and sand/rock layers. However, paleoecologists tend to avoid such settings and generally look for organic rich sediments where pollen, macrofossils, charcoals, and other paleobioindicators are well preserved and present in abundance. The presence of macrofossils in abundance facilitates radiocarbon dating of sediments. Coring such lakes and water bodies could be done using a lightweight coring equipment comprising a 
Kajak-Brinkhurst [6] for the topmost water saturated sediments and a piston corer or a modified Livingstone piston corer for deep sediments [7].

Several laboratories have developed lightweight, inexpensive platforms of varying designs that could accommodate such coring equipment [8-12]. These platforms have been used to retrieve up-to-20 m sediment sequences below an up-to-20 m water column [13]. However, construction plans are not readily available, and the stability of lightweight boats is not always optimal.

The first model of the Light, Affordable, Stable, and Transportable (LAST) coring platform was designed and constructed in the Republic of Congo in 2015 during a field coring campaign [14]. Because of the low availability of boats and the limitations we were facing during this field campaign, such as remote coring locations only accessible by walking, few available spaces in transportation vehicles, and limited access to construction supplies, we developed the principles behind the LAST coring platform: Light, Affordable, Stable, and Transportable. In this technical note, we will present the design of the coring platform and discuss its uses and limitations. We provide a construction and assemblage plan in open access; the plan has no text, and it only contains illustrations and eight concise and clear construction steps that should make the development of the LAST coring platform easily accessible to speakers of any language.

\subsection{Light}

Our first aim was to develop a coring platform light enough to be transported by a helicopter or a small truck. Only wood is needed in the coring platform construction (Figure 1, Supplementary Materials 1). The total weight of the platform is estimated to be $67 \mathrm{~kg}$ when using Picea sp. wood (density of c. $0.45 \times 10^{3} \mathrm{~kg} \cdot \mathrm{m}^{-3}$ ), and could be as low as $31 \mathrm{~kg}$ when using a light tropical wood such as balsa (density of c. $0.16 \times 10^{3} \mathrm{~kg} \cdot \mathrm{m}^{-3}$ ). When using Picea sp., the LAST coring platform weight is composed of $26 \mathrm{~kg}$ for the $240 \times 120 \times 2 \mathrm{~cm}$ plywood sheet, $29 \mathrm{~kg}$ for the $240 \times 8.8 \times 3.8 \mathrm{~cm}$ lumber ( $2 \times 4$ inch lumber), $12 \mathrm{~kg}$ for the two inflatable mattresses, and $1 \mathrm{~kg}$ for the hardware (Supplementary Materials 1). The LAST coring platform made of Picea wood can accommodate two operators each weighing $\sim 80 \mathrm{~kg}$, one modified Livingstone piston corer, and $20 \mathrm{~m}$ of rods weighing $\sim 45 \mathrm{~kg}$. The LAST platform made of lighter wood may accommodate more equipment, but the platform is, by its design, supposed to be operated by only two people. We recommend a maximum live load of $200 \mathrm{~kg}$.

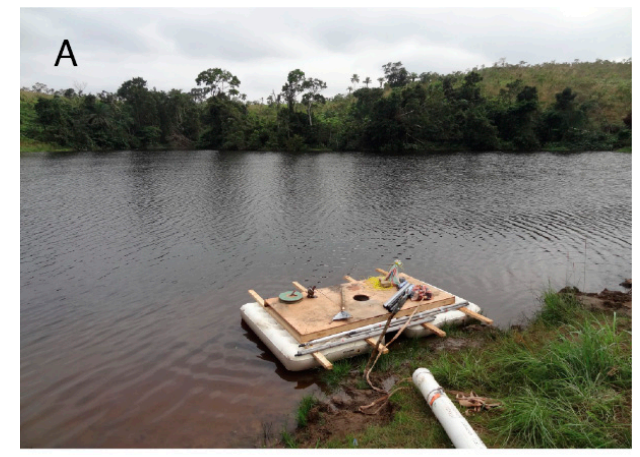

B

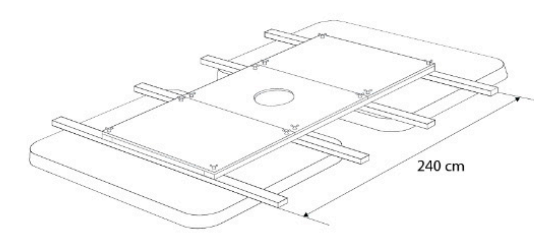

Figure 1. Picture (A, C Olivier Blarquez) and design (B) of the Light, Affordable, Stable, and Transportable (LAST) coring platform. For all dimensions and a complete construction plan, the reader is referred to Supplementary Materials 1. 


\subsection{Affordable}

Building the LAST coring platform should cost less than 300 USD in most countries. We usually used Coleman inflatable queen mattresses available worldwide for less than 50 USD. The Coleman DuraRest $^{\text {TM }}$ (USA) Plus Single High Airbed-Queen is advised for its durability [15], but any other brands or models can be used if the mattress size is at least $198 \times 147 \times 20 \mathrm{~cm}$ and the inflatable locking mechanism sufficiently leakproof. To avoid accidental air leak, we recommend mattresses with a screw type valve. Beyond the cost, one of our objectives was to use materials that could be sourced locally in most countries. Wood could be sourced locally and cut at appropriate dimensions, and hardware is generic and should be available worldwide. In Supplementary Materials 1, we provided Deutsches Institut für Normung (DNI) as well as International Organization for Standardization (ISO) codes when available for the hardware we used. These parts could be replaced with locally available equivalents. Tools used in the construction and assemblage of the LAST coring platform are minimal (a saw, a drill, a screwdriver, and a measuring tape) and available worldwide. These elements (affordability, availability) ensure that the LAST coring platform could be built locally and be available for laboratories in developing countries for which commercially available solutions might be difficult to acquire. Given that the LAST coring platform is affordable, its durability is generally not a concern; however, with minimal care, the wood structure and the mattresses could be used for several field campaigns without needing a replacement.

\subsection{Stable}

The stability of the platform during the coring process was an important feature of our design. Two people should be able to stand and operate the modified Livingstone piston corer adequately, i.e., drive rods, push the corer simultaneously to core the sediment, extract and retrieve the core, etc. The use of two inflatable mattresses has proven to be very useful to achieve high stability given the very large and flat contact area between the coring platform and water. During the coring process, the platform has almost no vertical movement. To avoid horizontal movement, it is important to anchor the platform properly. The anchoring is achieved using at least three anchors tied on three corners of the coring platform. Danforth fluke anchors or river anchors, weighing $\sim 15 \mathrm{~kg}$ each, are advised for anchoring in lakes with soft gyttja sediments. To provide a better stability and minimize sediment disturbance, each anchor line should be $\sim 5$ times as long as the water depth and composed of material with minimal stretch and water absorbance (e.g., polypropylene or polyester nylon). When specialized anchors are not available or transportation of heavy anchors is impossible, the use of "China bags" filled with dirt or rocks could represent an alternative. China bags are mass-produced, durable, and permeable, allowing them to sink easily when filled with dirt or rocks. The anchors must be sunk very slowly to avoid disturbing the sediment.

\subsection{Transportable}

Because of its low weight, the LAST coring platform is highly transportable either by land or air. The materials used to build the platform could be sourced locally in any countries, such that researchers planning foreign field coring campaigns only need to transport the tools and hardware, which will ease transportation logistic. The platform pieces of $120 \times 80 \mathrm{~cm}$ can be easily transported with a small truck, and the six pieces of lumber of $240 \mathrm{~cm}$ length can be transported along the coring device. The inflatable mattresses, each weighing $\sim 5 \mathrm{~kg}$, can be folded and transported in a backpack. Not only easily transported, the LAST coring platform is also easy to assemble and deploy in the field. When all the parts are constructed, the longest deployment step is inflating the mattresses, which can be sped up with a small foot pump. 


\section{Discussion}

The LAST coring platform has been tested in various situations and used to core 14 lakes and 2 rivers (Figure 2). The platform has been used in boreal Canada [16,17], in tropical Africa to core the Mara river [18], and to core two small shallow lakes in the Republic of Congo [14]. The LAST coring platform has been transported on foot, all-terrain vehicles, boat, helicopter, and pickup trucks. For example, the platform has been towed by a zodiac boat for more than $10 \mathrm{~km}$ along the Mara river in 2015. During all those field work campaigns, we never punctured any inflatable mattresses although we cored lakes with abundant shore vegetation. However, air mattresses are not engineered to standards used for inflatables intended for use as a flotation, and extra care should be taken when using air mattresses. In this respect, we advise users to wear life jackets at all times. In case of a puncture, the second mattress and the wood construction should enable the platform to remain afloat.

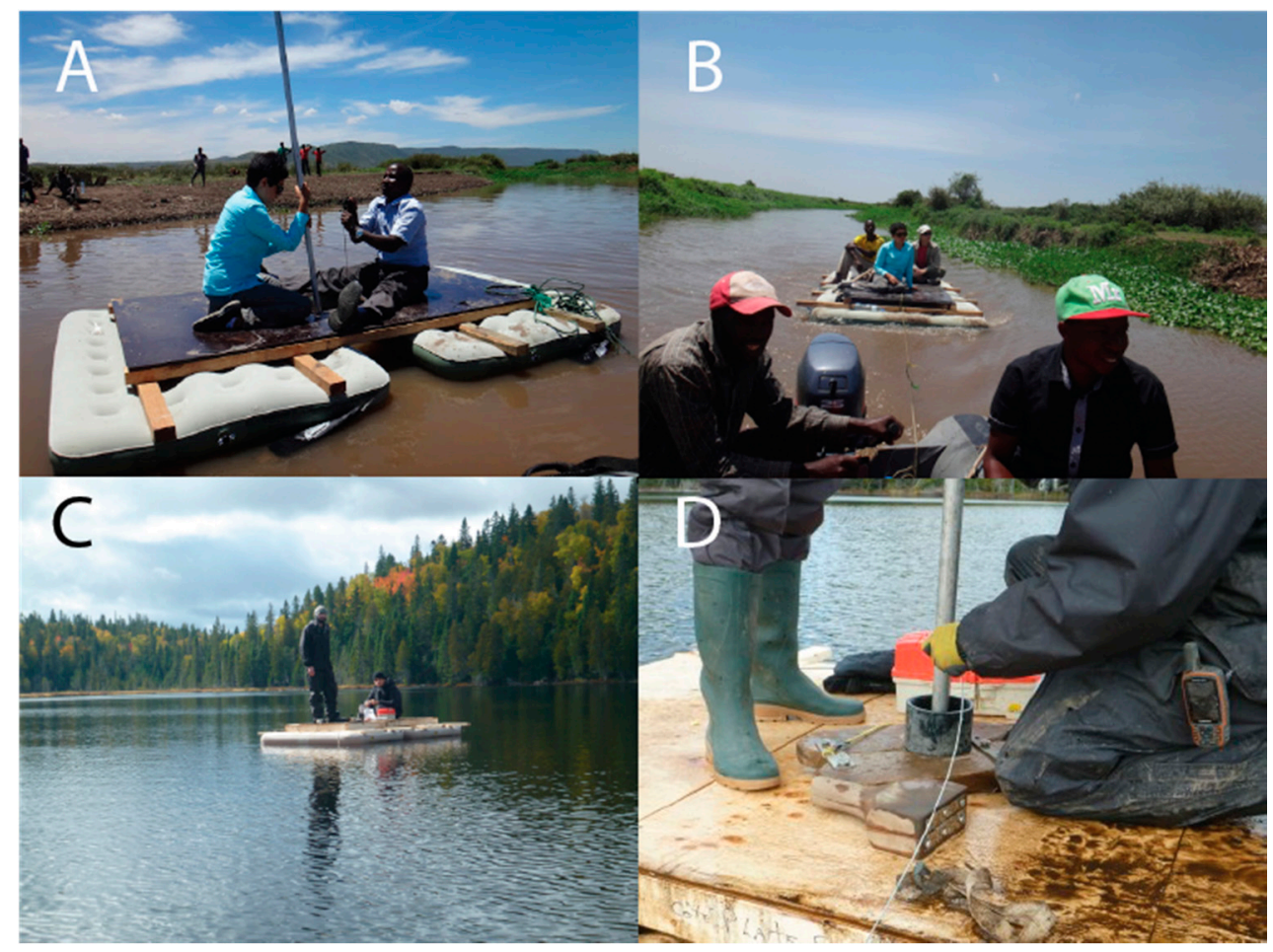

Figure 2. Examples of use of the LAST coring platform. Coring campaign of the Mara River in 2015 [18] using the LAST platform and a Russian corer (A, C Christopher Dutton). During this field campaign, the platform was towed by a boat between the several coring sites (B, (C) Christopher Dutton). The platform should be anchored at 3 points to achieve stability during the coring and when the water depth is too important (e.g., $>4 \mathrm{~m}$ ) a casing can be used, as shown in (C, (C) Olivier Blarquez) and (D, (C) Olivier Blarquez), respectively, during a coring campaign in boreal Canada.

During our testing, the maximum coring depth reached was $19 \mathrm{~m}$, i.e., $10 \mathrm{~m}$ of water depth and $9 \mathrm{~m}$ of sediment in Lac Labelle [16,17]. The sediment was composed of gyttja, and was therefore relatively easy to retrieve using a modified Livingstone piston corer. The bottom part of the deepest core $(\sim 60 \mathrm{~cm})$ was composed of laminated clay and silt accumulated during the late glacial and early Holocene, a common feature of lakes located under Pleistocene ice sheets [19]. When the water depth exceeded $4 \mathrm{~m}$, we used a casing composed of $2 \mathrm{~m}$ sections of PVC tubing $(\varnothing 15 \mathrm{~cm})$ to prevent the bending of the Livingstone corer rods. This casing was easily attached to the coring platform using ropes or chains. Retrieving very deep consolidated sediments can be challenging with a piston corer, and a percussion corer is recommended in that case. We did not test the coring platform with any percussion corer available on the market, although we believe that a tripod could be fitted on the 
platform to allow the use of such devices. We did also use the platform with a Russian corer. However, Russian corers are best used for peat bogs and not adapted for sampling lake gyttja.

When coring lakes and water bodies deeper than about $10 \mathrm{~m}$ and when the sediment is highly consolidated, a commercially available or custom heavy coring platform must be used. However, in all other situations, when small lakes with organic rich sediments are sought after, the Kajak-Brinkhurst corer, the modified Livingstone corer, and the LAST coring platform combo represent a viable and easy to deploy alternative.

Supplementary Materials: The following are available online at http://www.mdpi.com/2571-550X/3/3/27/s1.

Author Contributions: O.B. and J.A. designed the LAST coring platform, and O.B. wrote the manuscript and designed the figures that were commented and modified by J.A. All authors have read and agree to the published version of the manuscript.

Funding: This research was funded by a NSERC discovery grant (RGPIN-2017-05062) to O.B.

Acknowledgments: We thank all the students and collaborators who extensively tested and helped to design the LAST coring platform. We warmly thank two anonymous reviewers, whose recommendations were extremely useful to improve the manuscript.

Conflicts of Interest: The authors declare no conflict of interest.

\section{References}

1. Birks, H.H. Bringing Palaeoecology Alive. In Curious about Nature: A Passion for Fieldwork; Cambridge University Press: Cambridge, UK, 2020; p. 146.

2. Kullenberg. Available online: http://lrc.geo.umn.edu/laccore/kullenberg.html (accessed on 1 September 2020).

3. Lake Barombi Mbo Coring Campaign. Available online: http://www.uwitec.at/html/gallery.html (accessed on 1 September 2020).

4. Garcin, Y.; Deschamps, P.; Ménot, G.; De Saulieu, G.; Schefuß, E.; Sebag, D.; Dupont, L.M.; Oslisly, R.; Brademann, B.; Mbusnum, K.G.; et al. Early anthropogenic impact on Western Central African rainforests 2600 y ago. Proc. Natl. Acad. Sci. USA 2018, 115, 3261-3266. [CrossRef] [PubMed]

5. Ledoux, G.; Lajeunesse, P.; Chapron, E.; St.-Onge, G. Multibeam bathymetry investigations of mass movements in Lake Le Bourget (NW Alps, France) using a portable platform. In Submarine Mass Movements and Their Consequences-4th International Symposium; Springer: Dordrecht, The Netherlands, 2010; Volume 28, pp. 423-434.

6. Blomqvist, S.; Abrahamsson, B. An improved Kajak-type gravity core sampler for soft bottom sediments. Swiss J. Hydrol. 1985, 47, 81-84. [CrossRef]

7. Cushing, E.J.; Wright, H.E. Hand-Operated Piston Corers for Lake Sediments. Ecology 1965, 46, 380-384. [CrossRef]

8. Inner Tube. Available online: http://lrc.geo.umn.edu/laccore/innertube.html (accessed on 1 September 2020).

9. Cataraft. Available online: https://csdco.umn.edu/equipment/cataraft (accessed on 1 September 2020).

10. Coring Platform. Available online: https://www.eurekalert.org/multimedia/pub/116149.php?from=328511 (accessed on 1 September 2020).

11. Schimmelmann, J.; Nguyễn-Văn, H.; Nguyễn-Thuỳ, D.; Schimmelmann, A. Low Cost, Lightweight Gravity Coring and Improved Epoxy Impregnation Applied to Laminated Maar Sediment in Vietnam. Geosciences 2018, 8, 176. [CrossRef]

12. Lake Coring Equipment. Available online: https://ecologyofthepast.info/2013/07/17/lake-coring-equipment/ (accessed on 1 September 2020).

13. Hillyer, R.; Valencia, B.G.; Bush, M.B.; Silman, M.R.; Steinitz-Kannan, M. A 24,700-yr paleolimnological history from the Peruvian Andes. Quat. Res. 2009, 71, 71-82. [CrossRef]

14. Aleman, J.C.; Blarquez, O.; Elenga, H.; Paillard, J.; Kimpuni, V.; Itoua, G.; Issele, G.; Staver, A.C. Palaeo-trajectories of forest savannization in the southern Congo. Biol. Lett. 2019, 15, 20190284. [CrossRef] [PubMed]

15. Coleman Durarest. Available online: https://www.coleman.com/all-camp-furniture/airbeds/durarest-extrahigh-airbed-queen/col_2000020875_pr/COL_2000020875 (accessed on 1 September 2020). 
16. Girardin, M.; Portier, J.; Rémy, C.; Ali, A.; Paillard, J.; Blarquez, O.; Asselin, H.; Gauthier, S.; Grondin, P.; Bergeron, Y. Coherent signature of warming-induced extreme sub-continental boreal wildfire activity 4800 and 1100 years BP. Environ. Res. Lett. 2019. [CrossRef]

17. Paillard, J. Dynamique Holocène de L'érable à Sucre (Acer Saccharum Marsh.) Dans L'ouest du Québec. Master's Thesis, Université du Québec en Abitibi-Témiscamingue, Rouyn-Noranda, QC, Canada, December 2018.

18. Dutton, C.L.; Subalusky, A.L.; Hill, T.D.; Aleman, J.C.; Rosi, E.J.; Onyango, K.B.; Kanuni, K.; Cousins, J.A.; Staver, A.C.; Post, D.M. A 2000-year sediment record reveals rapidly changing sedimentation and land use since the 1960s in the Upper Mara-Serengeti Ecosystem. Sci. Total Environ. 2019, 664, 148-160. [CrossRef] [PubMed]

19. Richard, P.J.H.; Occhietti, S. 14C chronology for ice retreat and inception of Champlain Sea in the St. Lawrence Lowlands, Canada. Quat. Res. 2005, 63, 353-358. [CrossRef]

(C) 2020 by the authors. Licensee MDPI, Basel, Switzerland. This article is an open access article distributed under the terms and conditions of the Creative Commons Attribution (CC BY) license (http://creativecommons.org/licenses/by/4.0/). 